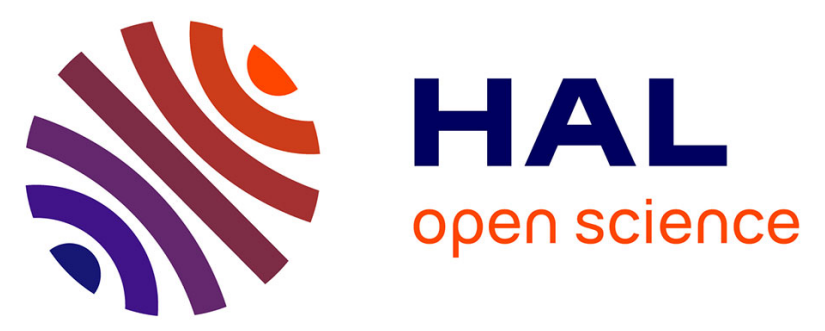

\title{
A LA-ICP-MS sulphide calibration standard based on a chalcogenide glass
}

Lihua Ding, Guang Yang, Fang Xia, Claire E. Lenehan, Gujie Qian, Aoife Mcfadden, Joë L. Brugger, Xianghua Zhang, Guorong Chen, Allan Pring

\section{- To cite this version:}

Lihua Ding, Guang Yang, Fang Xia, Claire E. Lenehan, Gujie Qian, et al.. A LA-ICP-MS sulphide calibration standard based on a chalcogenide glass. Mineralogical Magazine, 2011, 75 (2), pp.279-287. 10.1180/minmag.2011.075.2.279 . hal-00719682

\section{HAL Id: hal-00719682 https://hal.science/hal-00719682}

Submitted on 19 Nov 2019

HAL is a multi-disciplinary open access archive for the deposit and dissemination of scientific research documents, whether they are published or not. The documents may come from teaching and research institutions in France or abroad, or from public or private research centers.
L'archive ouverte pluridisciplinaire HAL, est destinée au dépôt et à la diffusion de documents scientifiques de niveau recherche, publiés ou non, émanant des établissements d'enseignement et de recherche français ou étrangers, des laboratoires publics ou privés. 


\title{
A LA-ICP-MS sulphide calibration standard based on a chalcogenide glass
}

\author{
Lihua Ding ${ }^{1}$, Guang Yang $^{1,6}$, Fang Xia $^{2,3}$, Claire E. Lenehan ${ }^{4}$, Gujie Qian ${ }^{3,5}$, Aoife McFadden ${ }^{3}$, \\ JoËl Brugger ${ }^{2,3}$, Xianghua Zhang ${ }^{6}$, Guorong Chen $^{1, *}$ and Allan Pring ${ }^{2,3, *}$ \\ 1 Key Laboratory for Ultrafine Materials of Ministry of Education, School of Materials Science and Engineering, \\ East China University of Science and Technology, Shanghai 200237, China \\ 2 Tectonics, Resources and Exploration (TRaX), School of Earth and Environmental Sciences, University of \\ Adelaide, North terrace, Adelaide, SA 5005, Australia \\ 3 Department of Mineralogy, South Australian Museum, North Terrace, Adelaide, SA 5000, Australia \\ 4 School of Chemical and Physical Sciences, Flinders University, GPO Box 2100 Adelaide, SA 5001, Australia \\ 5 Ian Wark Research Institute, University of South Australia, Mawson Lakes, SA 5095, Australia \\ 6 Laboratoire des Verres et Céramiques, UMR-CNRS 6226, Université de Rennes 1, Rennes Cedex 35042, France
}

The accurate measurement of trace element concentrations in natural sulphides by laser ablation inductively coupled plasma mass spectrometry (LA-ICP-MS) has been limited by the lack of matrixmatched calibration standards. The synthesis of a standard, IMER-1, by incorporating four minor and 34 trace elements into a chalcogenide glass matrix $\mathrm{Ge}_{28} \mathrm{Sb}_{12} \mathrm{~S}_{60}$ is reported here. Chemical analysis by electron probe microanalysis (EPMA), LA-ICP-MS, solution ICP-MS, and inductively coupled plasmaoptical emission spectroscopy (ICP-OES) confirmed the excellent homogeneity of major elements (1- $\sigma$ relative standard deviation (RSD) $<1 \%$ for $\mathrm{S}, \mathrm{Sb}$ and $\mathrm{Ge}$ ) and acceptable homogeneity of most trace elements $(1-\sigma$ RSD $<10 \%)$. The standard was validated by analysing trace-elements concentrations in three geological pyrite specimens using IMER-1 as the calibration standard and comparing the results to previously reported values also determined by LA-ICP-MS but using a different calibration standard, STDGL2b-2. The results suggest that IMER-1 may be an appropriate calibration standard for LA-ICPMS analysis of trace elements in natural sulphides.

KEYwORDs: Ge-Sb-S chalcogenide glasses, LA-ICP-MS, sulphide calibration standard, trace element analysis.

\section{Introduction}

THE determination of trace-element concentrations and spatial distribution in geological samples is an important ongoing research topic in the geochemical community (Ciobanu et al., 2009; Cook et al., 2009) because the trace-element chemistry often records critical information for understanding

* E-mail addresses:

A. Pring: allan.pring@samuseum.sa.gov.au;

G. Chen: grchen@ecust.edu.cn

DOI: 10.1180/minmag.2011.075.2.279 geochemical processes including ore formation and mineral-phase re-equilibration (Zou, 2007). Laser-ablation inductively coupled plasma mass spectrometry is an ideal technique for this purpose because of its direct multi-element analysis ability with down-to-ppb-level detection limit and microscale spatial resolution (typically $20-100 \mu \mathrm{m}$ ), providing a cheap and accurate routine measurement method for geochemical laboratories (Norman et al., 2003). The application of LA-ICP-MS, however, relies largely on the availability of matrix-matched calibration standards because the ablation behaviour of a standard can be very different to the unknown materials due to the different matrix which may result in 
inaccurate analysis (Ridley and Lichte, 1998). For natural sulphides, no commercial standards are available because of the challenge in preparing homogeneous and matrix-matched standards. For this reason, several geochemical laboratories have attempted to develop in-house sulphide standards for LA-ICP-MS but all have limitations. For example, obtaining an homogeneous standard is possible by fusing sulphides into a lithium borate glass but matrix-match to natural sulphides remains problematic and the loss of volatile species is difficult to avoid during fusion (Danyushevsky et al., 2003). Matrix-matched standards can be prepared by synthesizing Fedeficient 1C-pyrrhotite doped with platinumgroup elements (PGE) to form solid solutions but homogeneity is not readily achieved and elements not in the PGE group can be very difficult to incorporate (Ballhaus and Sylvester, 2000; Cabri et al., 2003; WohlgemuthUeberwasser et al., 2007). Graphite electrodes welding of natural pyrite with added trace elements can also produce a matrix-matched standard but similar heterogeneity issues exist (Dewaele et al., 2007). A cold-pressed pellet of amorphous $\mathrm{Fe}-\mathrm{Cu}-\mathrm{Zn}$ sulphide standard can be synthesized by precipitating a sulphate solution containing aqueous metal species (Wilson et al., 2002), but the dark unpolishable surface makes focusing the laser difficult and the heterogeneous distributions of some important metal elements (e.g. Au, RSD $88 \%$ for $50 \mu \mathrm{m}$ spot size) are still problems.

The lack of a LA-ICP-MS standard for traceelement analysis of sulphide ores gave rise to this work and we have attempted to synthesize a sulphur-based chalcogenide glass standard, denoted as IMER-1, by doping with four minor elements and 34 trace elements. This standard is complementary to other available standards in that it contains more elements, including the homogeneously distributed $\mathrm{Au}$, and lower element concentrations.

\section{Experimental}

\section{Synthesis}

The preparation of IMER-1 was a two-step process. The first step was the synthesis of a trace-elements-doped $\mathrm{Fe}-\mathrm{Cu}-\mathrm{Zn}$ sulphide mixture. The second step was the synthesis of IMER-1 by distributing homogeneously the sulphide mixture in a sulphur-based chalcogenide glass, $\mathrm{Ge}_{28} \mathrm{Sb}_{12} \mathrm{~S}_{60}$.
The trace-elements-doped $\mathrm{Fe}-\mathrm{Cu}-\mathrm{Zn}$ sulphide mixture was synthesized by the wet chemical method. High-purity hydrated sulfate salts were dissolved in deionized water and doped with certified Atomic Spectroscopy standards. These were then reacted with aqueous solutions of highpurity sodium sulphide to yield a black precipitate. A detailed description of the method can be found in Wilson et al. (2002). The doped minor and trace elements in $\mathrm{Fe}-\mathrm{Cu}-\mathrm{Zn}$ sulphide include $\mathrm{Na}, \mathrm{As}, \mathrm{Ba}, \mathrm{Bi}, \mathrm{Br}, \mathrm{Cr}, \mathrm{Cd}, \mathrm{Cl}, \mathrm{Co}, \mathrm{Ga}, \mathrm{Au}, \mathrm{Mn}$, In, I, Ir, Pb, Hg, Mo, Ni, Os, Pd, Pt, K, Cs, Re, Rh, $\mathrm{Se}, \mathrm{Ag}, \mathrm{Sr}, \mathrm{Te}, \mathrm{Tl}, \mathrm{Sn}, \mathrm{V}, \mathrm{W}$ and U. The concentrations of these trace elements in the mixture were estimated to be a few hundred ppm.

The IMER-1 glassy standard was then synthesized by melting a mixture of three high-purity glass-forming elements ( $\mathrm{Ge}$ and S, 99.999\%, Sb, 99.9999\%, Emei Semiconductor Material Factory, China) together with a small amount of the traceelements-doped $\mathrm{Fe}-\mathrm{Cu}-\mathrm{Zn}$ sulphide mixture using the melt-quenching method (Zhao et al., 2005; Xia et al., 2006). A glass with the composition $\mathrm{Ge}_{28} \mathrm{Sb}_{12} \mathrm{~S}_{60}$ was chosen as the matrix for hosting the trace elements. This composition has an excellent glass-forming ability (Xia et al., 2006) and its sulphur concentration closely matches those of the natural sulphide samples. The sulphur concentration in the Ge-Sb-S glass system can be adjusted in the compositional range 50-75 at.\%.

In detail, IMER-1 was prepared using the following procedure. First, $10 \mathrm{~g}$ of starting materials for the glass composition, $\mathrm{Ge}_{28} \mathrm{Sb}_{12} \mathrm{~S}_{60}$, and $0.2 \mathrm{~g}$ of trace-elements-doped $\mathrm{Fe}-\mathrm{Cu}-\mathrm{Zn}$ sulphide mixture were weighed to better than $1 \%$ precision, mixed until homogeneous and sealed in an evacuated silica tube using an oxy-coal gas flame. Then, the charge was placed in a rocking furnace and heated stepwise to $250^{\circ} \mathrm{C}\left(4^{\circ} \mathrm{C} / \mathrm{min}\right), 450^{\circ} \mathrm{C}\left(1.7^{\circ} \mathrm{C} / \mathrm{min}\right)$, and $650^{\circ} \mathrm{C}$ $\left(1.7^{\circ} \mathrm{C} / \mathrm{min}\right)$, holding for $30 \mathrm{~min}$ at each temperature to minimize tube failure due to high $\mathrm{S}$ vapour pressure. The charge was then heated to $950^{\circ} \mathrm{C}\left(1.2^{\circ} \mathrm{C} / \mathrm{min}\right)$ and held for $10 \mathrm{~h}$ to produce an homogeneous melt. It was then cooled to $850^{\circ} \mathrm{C}$ $\left(-0.5^{\circ} \mathrm{C} / \mathrm{min}\right)$ and held for a further $2 \mathrm{~h}$ to prevent the formation of bubbles, with subsequent rapid quenching in cold water to obtain a black glass rod. Finally, the glass was annealed at $220^{\circ} \mathrm{C}$ for $2 \mathrm{~h}$ to remove the inner stress induced in the quenching step. Part of the glass rod (Fig. 1) was crushed into small fragments (a few mm across), embedded in epoxy resin, and polished for further characterization. 


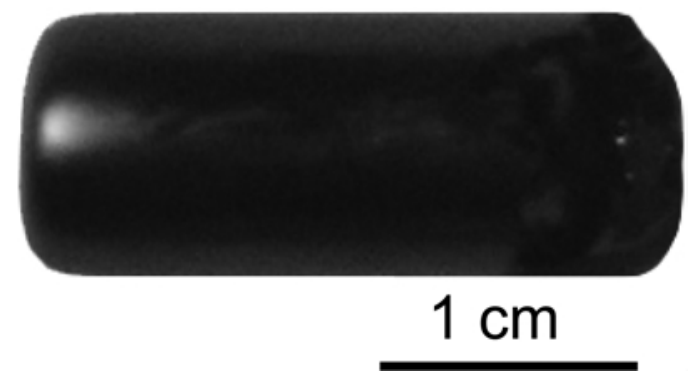

FIG. 1. Photo of the synthesized IMER-1 glass rod.

\section{Characterization methods}

The glassy state of IMER-1 was checked by powder X-ray diffraction (XRD) on a Huber Guinier Image Plate G670 with Co- $K \alpha_{1}$ radiation $(\lambda=1.78892 \AA)$. A powder diffraction pattern was collected for $3600 \mathrm{~min}$ to enable trace amounts of crystalline phases to be resolved if present.

The compositional homogeneity of IMER-1 was characterized by a number of methods, including optically, using a thermal-imaging camera, field emission scanning electron microscopy (FESEM) imaging, electron probe microanalysis (EPMA), and time-resolved LA-ICP-MS. A Philips XL 30 FESEM was operated under backscattered electron (BSE) mode. The accelerating voltage was maintained at $20 \mathrm{kV}$ as a good compromise between spatial resolution and chemical sensitivity.

The spatial homogeneity and concentrations of the major elements $(\mathrm{Ge}, \mathrm{Sb}, \mathrm{S})$ were determined by EPMA ( 88 spot analyses from eight line scans on four IMER-1 fragments) using a Cameca SX-51 instrument. Operating conditions were an accelerating voltage of $20 \mathrm{kV}$ and a beam current of $20 \mathrm{nA}$. Standards (element energy level, counting time) used for each element were: $\mathrm{Ge}$ (Ge-K $\alpha, 10 \mathrm{~s}$ ), $\mathrm{Sb}_{2} \mathrm{Te}_{3}\left(\mathrm{Sb}-L \alpha, 10 \mathrm{~s}\right.$ ), and $\mathrm{CuFeS}_{2}$

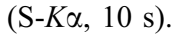

The spatial homogeneity of major, minor and trace elements in IMER-1 was assessed using an Agilent $7500 \mathrm{cx}$ ICP-MS instrument with attached New Wave Nd: YAG $213 \mathrm{~nm}$ UV laser. An assessment of the elemental homogeneity of the IMER-1 standard was conducted by determining the spatial distribution of net counts per second (CPS) because net CPS is directly proportional to elemental concentration. Two approaches were applied: (1) spot analysis, and (2) time-resolved line scan. In spot analyses, 30 spots with a diameter of $100 \mu \mathrm{m}$ and 23 spots with a diameter of $60 \mu \mathrm{m}$, on randomly selected locations, were performed with the laser repetition rate of $5 \mathrm{~Hz}$. Due to the low concentration of the elements in the standards, such large beam sizes must be used to obtain a sufficiently high CPS value to reduce counting-statistics errors. The acquisition time for each spot was $70 \mathrm{~s}$, which included an initial $25 \mathrm{~s}$ measurement of the carrier gas background before the laser was switched on. The CPS value of the elements was first corrected using ${ }^{34} \mathrm{~S}$ as the internal standard in which we assumed homogeneous distribution of S in IMER-1 (1- $\sigma$ RSD $0.78 \%$ for S, refer to EPMA results in Table 1). The ${ }^{34} \mathrm{~S}$ internal standard was used to overcome drift of instrument sensitivity and the variation of ablation yields during spot-to-spot analysis. Then, the corrected sample CPS was averaged over $35 \mathrm{~s}$ of the signal region in the time-resolved spectra, and finally, the averaged background was subtracted to obtain the net CPS. The net CPS from such data-processing procedure reduces the inherent instrumental analytical errors to minimum levels in the hope that any deviations of net CPS from spot-to-spot analysis mainly reflect the homogeneity of the elemental distribution. In time-resolved line scans, eight lines on four IMER-1 grains were scanned with the beam size of $60 \mu \mathrm{m}$, scan speed of $3.5 \mu \mathrm{m} / \mathrm{s}$, and laser repetition rate of $5 \mathrm{~Hz}$. Here the CPS was raw counts without internal standard correction and background subtraction.

The absolute concentrations of the minor and trace elements were determined by LA-ICP-MS, solution ICP-MS, and ICP-OES. Minor elements: $\mathrm{Cu}, \mathrm{Fe}, \mathrm{Zn}$ and trace elements $\mathrm{V}, \mathrm{Cr}, \mathrm{Co}, \mathrm{Ni}, \mathrm{Ga}$, As, Se, Mo, Ag, Cd, In, Te, Ba, W, Au, Tl, Pb and $\mathrm{Bi}$ in IMER-1 were determined using the same LA-ICP-MS setup and data-reduction procedure described above and the USGS standard MASS-1 as the calibration standard (Wilson et al., 2002)

TABLE 1. Major-element concentrations and 1- $\sigma$ relative standard deviations (RSD) of IMER-1 determined by 88 EPMA spot analyses.

\begin{tabular}{lccc} 
Element & Averaged wt.\% & Averaged at.\% & RSD (\%) \\
\hline $\mathrm{Ge}$ & 36.55 & 27.24 & 0.68 \\
$\mathrm{Sb}$ & 26.92 & 11.96 & 0.83 \\
$\mathrm{~S}$ & 35.66 & 60.16 & 0.78
\end{tabular}


with ${ }^{34} \mathrm{~S}$ as an internal standard. Fifteen spot analyses on randomly selected locations in IMER-1 were performed. The laser repetition rate was set to $5 \mathrm{~Hz}$ and the spot size was set to $60 \mu \mathrm{m}$. The acquisition time for each spot was $70 \mathrm{~s}$, including an initial $25 \mathrm{~s}$ measurement of the carrier gas background before the laser was switched on. The concentrations of trace elements (Cr, Mn, Co, Ni, Ga, As, Se, Sr, Ag, Cd, In, Te, $\mathrm{Ba}, \mathrm{Au}, \mathrm{Hg}, \mathrm{Tl}, \mathrm{Bi}$ ) were determined by solution ICP-MS (Agilent 7500ce) using internal standards ${ }^{89} \mathrm{Y},{ }^{45} \mathrm{Sc},{ }^{141} \mathrm{Pr}$ or ${ }^{169} \mathrm{Tm}$ depending on the element analysed. This involved taking $1 \mathrm{~g}$ of IMER-1, crushing it into a fine powder, followed by digestion in the microwave in aqua regia solution $\left(\mathrm{HNO}_{3}: \mathrm{HCl}=1: 3\right)$, which was prepared using high-purity acids. The solution was then diluted with Milli-Q water for solution ICP-MS analysis. Minor-elements $(\mathrm{Cu}, \mathrm{Fe}, \mathrm{Zn}, \mathrm{Na})$ concentrations were determined by ICP-OES using a Spectro Arcos ICP spectrometer. The solution-preparation procedure was the same as for solution ICP-MS. Neutron activation analysis is a widely used characterization method for standards but for IMER-1 it was not possible due to the high $\mathrm{Sb}$ content (26.5 wt.\%), which becomes too active during irradiation to permit measurement of the trace elements.

The IMER-1 standard was further validated by analysing trace-elements concentrations in three geological pyrite specimens (Sunrise Dam, Western Australia) using IMER-1 as the calibration standard and comparing the results to the previous reported values by Sung (2009) also determined by LA-ICP-MS but using a different calibration standard, STDGL2b-2 (CODES,

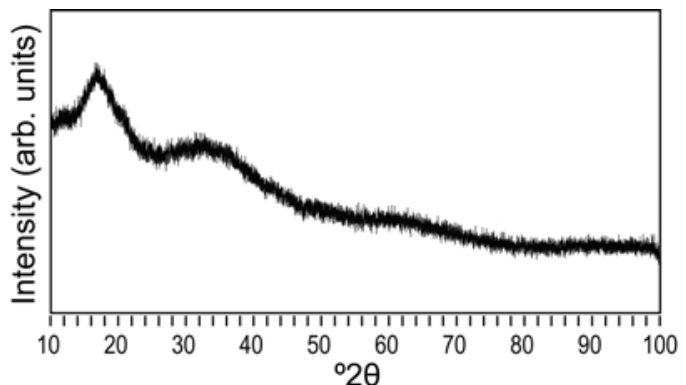

FIG. 2. XRD pattern (3600 min X-ray exposure) of IMER-1, showing the glassy state without any crystalline phases.

University of Tasmania). The spot size was set to $60 \mu \mathrm{m}$, the laser repetition rate was set to $5 \mathrm{~Hz}$, and the acquisition time set to $70 \mathrm{~s}$, including $25 \mathrm{~s}$ background measurements. The spots analysed were selected adjacent to the previously analysed points.

\section{Results and discussion}

The powder XRD analysis confirmed that IMER-1 is a typical chalcogenide glass with intermediate range order $(10-20 \AA)$ of the glass network (Xia et al., 2008), and without any crystalline phases (Fig. 2). Careful observation using the thermalimaging camera showed no optical heterogeneity. Backscattered electron images from the FESEM from a number of different fragments show no chemical contrast apart from several bubbles, suggesting very homogeneous major-element composition (Fig. 3).
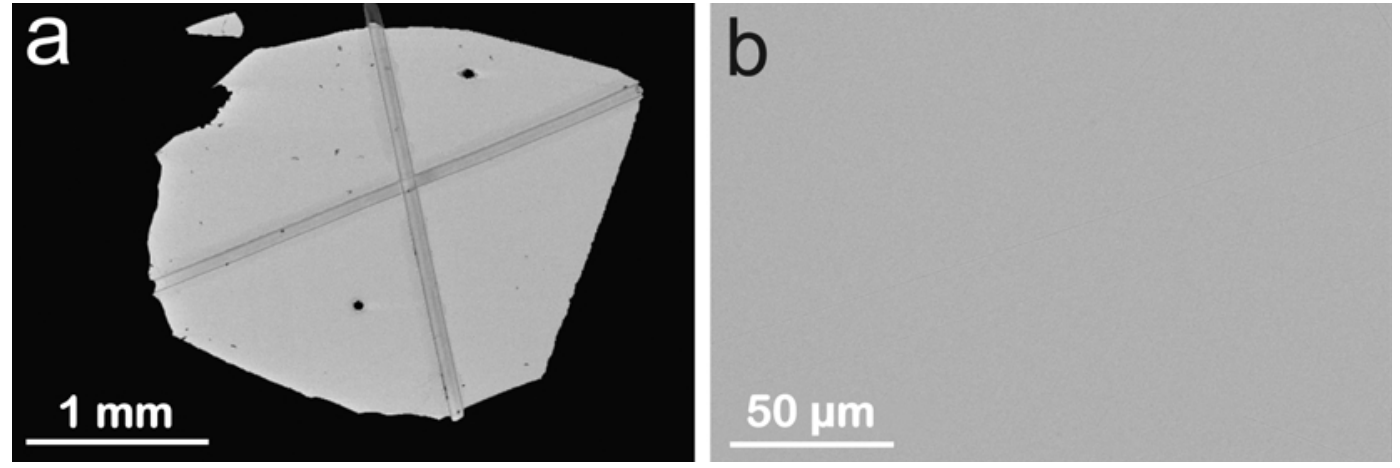

FIG. 3. Backscattered electron micrographs of polished cross-sections of IMER-1. (a) A typical grain showing two laser ablated spots and two traces of time resolved line scans after LA-ICP-MS. (b) An enlarged view showing no chemical contrast. 
The concentrations and spatial distributions of the major elements determined by EPMA line scans are summarized in Table 1 . The atomic ratio among the three glass-forming elements is $\mathrm{Ge}: \mathrm{Sb}: \mathrm{S} \approx 27: 12: 61$, very close to the theoretical glass composition $\mathrm{Ge}_{28} \mathrm{Sb}_{12} \mathrm{~S}_{60}$. The slight difference is due to the error involved during the weighing of starting materials. The $1-\sigma$ relative standard deviations (RSD) of the three elements are all $<1 \%$ (Table 1 ). Such small deviations are within the X-ray counting statistics errors, calculated as $2.32 \%$ for $\mathrm{Ge}, 2.52 \%$ for $\mathrm{Sb}$, and $1.56 \%$ for $\mathrm{S}$ (Reed, 2005), indicating that the spatial distributions of $\mathrm{Ge}, \mathrm{Sb}$ and $\mathrm{S}$ are very homogeneous.

The bulk absolute concentrations of minor and trace elements determined by various methods (LA-ICP-MS, solution ICP-MS, and ICP-OES) are summarized in Table 2. The concentrations of most trace elements are much lower than expected. This is probably due to the fact that relatively small contents of trace elements coprecipitated with the $\mathrm{Fe}-\mathrm{Cu}-\mathrm{Zn}$ sulphide mixture during wet chemical synthesis, and it was difficult to incorporate more than $2 \mathrm{wt} . \%$ of the sulphide mixture into the glass.

The results of LA-ICP-MS characterization of spatial homogeneity are shown in Fig. 4. It is generally seen that RSD decreases when the beam size increases from $60 \mu \mathrm{m}$ to $100 \mu \mathrm{m}$, which is the result of the reduction of countingstatistics error when a larger beam size is applied. When the $100 \mu \mathrm{m}$ beam size was used, the RSD for all 26 elements is $<15 \%$ and for 22 elements $<10 \%$; when the $60 \mu \mathrm{m}$ beam size was used, the
RSD for all 26 elements was $<30 \%$ and for 16 elements was $<15 \%$. This suggests that a large beam should be used for this standard to reduce counting-statistics errors. The RSD for Ir, Os, K, $\mathrm{Cs}, \mathrm{Re}, \mathrm{Sn}$ and $\mathrm{U}$ are $>40 \%$, indicating extensive heterogeneous distributions. These elements are not included in the plot. Note that RSDs in Fig. 4 involve not only element homogeneity but also instrumental analytical errors such as instrumental drifts and detector counting statistics. The instrumental drift was minimized by using ${ }^{34} \mathrm{~S}$ as the internal standard. To reflect RSD from the element homogeneity, the counting-statistics errors, as approximated by $\mathrm{CPS}^{-0.5}$ (Norman et $a l ., 2003)$, have been plotted $v s$. CPS along with the elements scattered in the same plot (Fig. 5). All the elements are distributed above the counting statistics curve, indicating additional errors from element distribution. Most elements are close to the counting statistics curve, however, indicating the reasonably good homogeneity of the element distributions. For example, excluding RSD from counting statistics, the RSD for $\mathrm{Au}$ is only $1.43 \%$. The CPS variation as a function of time during the time-resolved line scan, as shown in Fig. 6, gives similar results, showing excellent homogeneity of the major elements (RSD $<3 \%$ ) and reasonable homogeneity of the trace elements (RSD $<15 \%$ ). The quality of this sulphide standard is comparable to those NIST silicate standards with similar traceelements concentrations. For example, in the NIST-614 and NIST-616 silicate standards, most trace elements have an RSD $<15 \%$ (Norman et al., 1996).

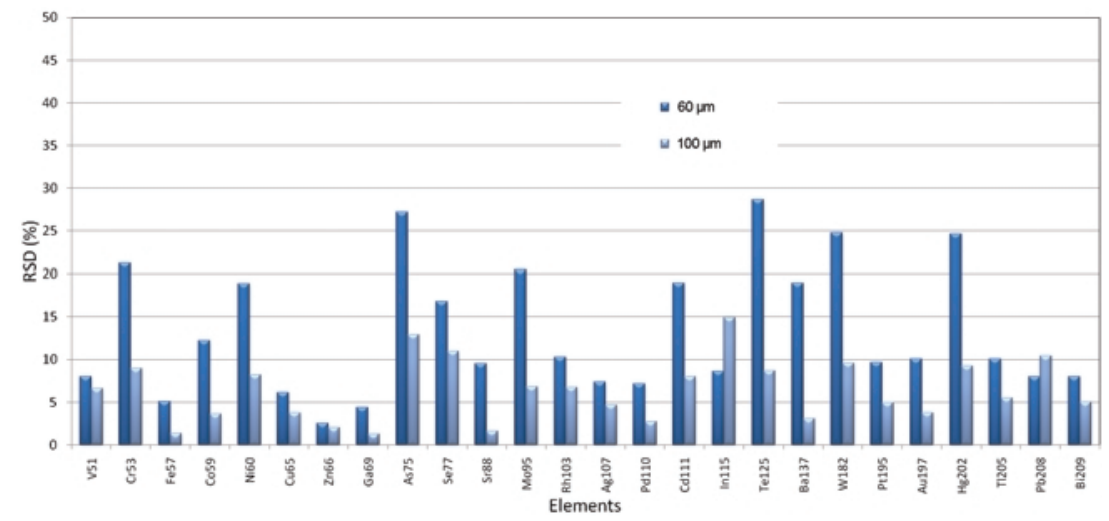

Fig. 4. Relative standard deviations (RSD) of counts per second (CPS) of elements from LA-ICP-MS analyses, showing varying spatial homogeneity. RSD for $60 \mu \mathrm{m}$ and $100 \mu \mathrm{m}$ were calculated from 23 spot and 30 spot analyses, respectively. CPS were corrected based on the assumption of constant CPS of S. 


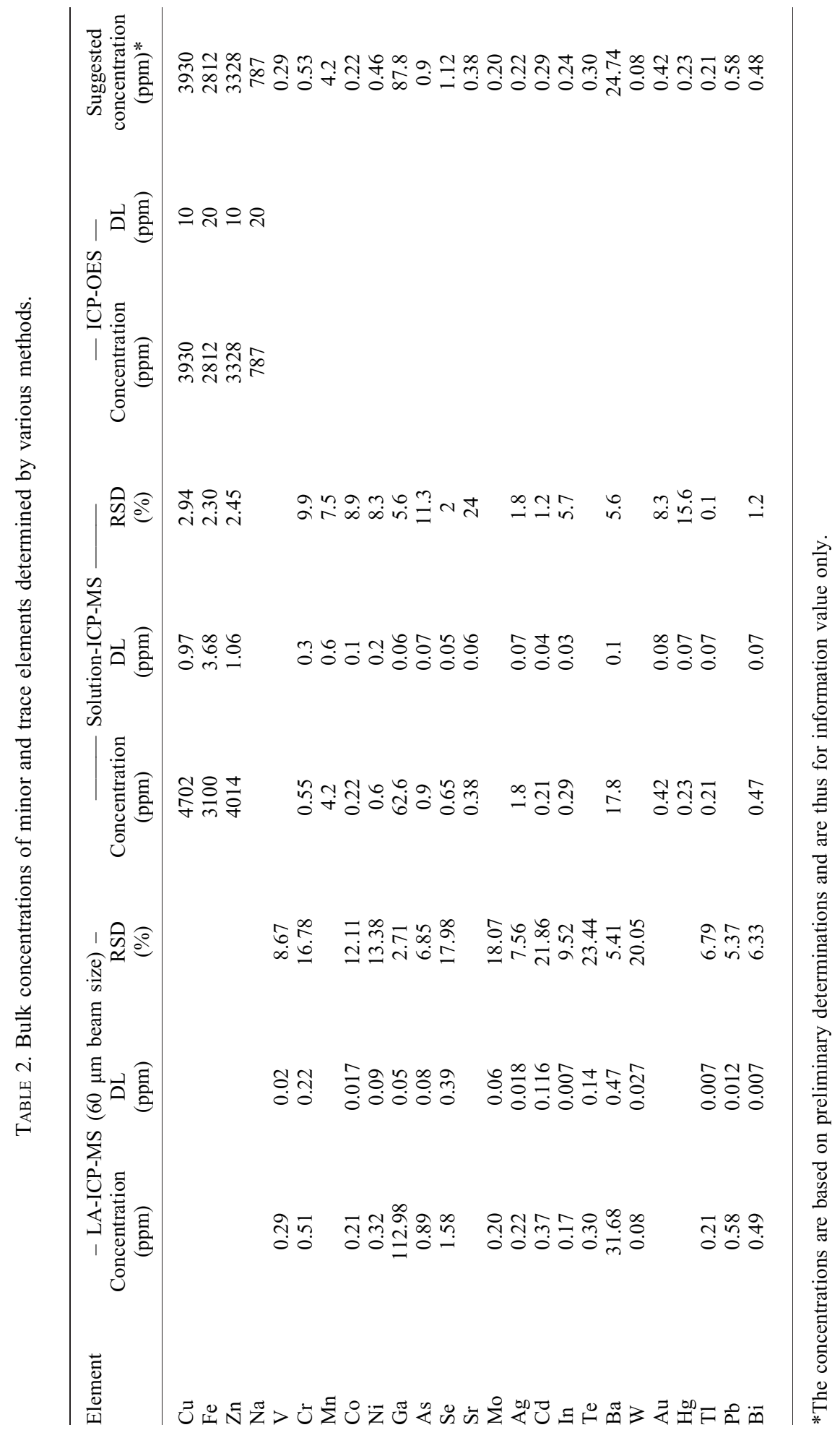




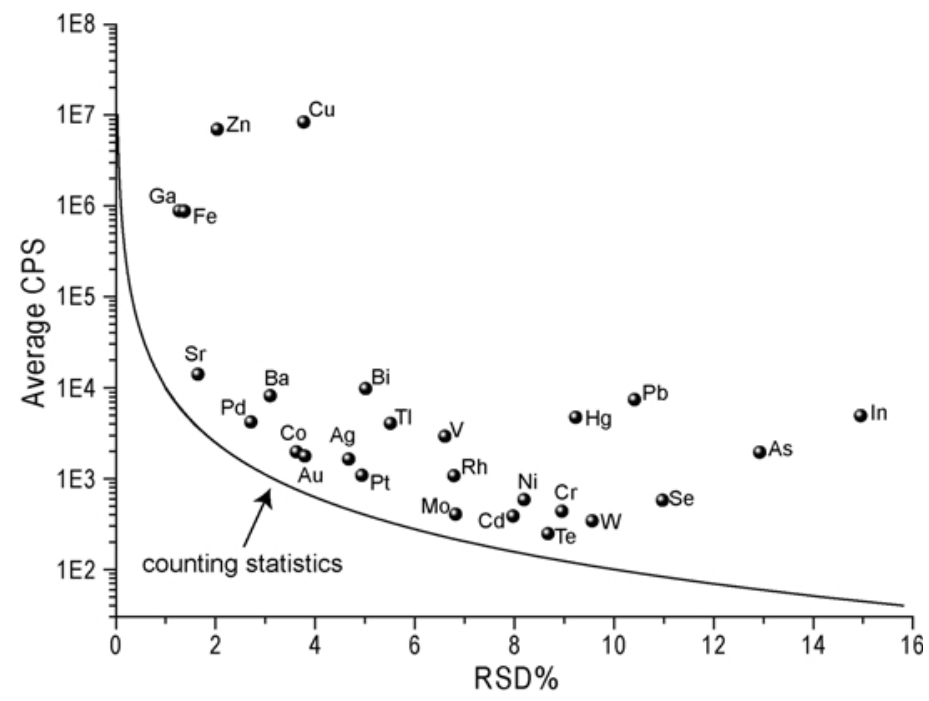

FIG. 5. The overall RSD $\%(100 \mu \mathrm{m}$ spot size $)$ of the elements and the counting statistics curve.

A comparison of the measurements of the trace-element concentrations in three geological

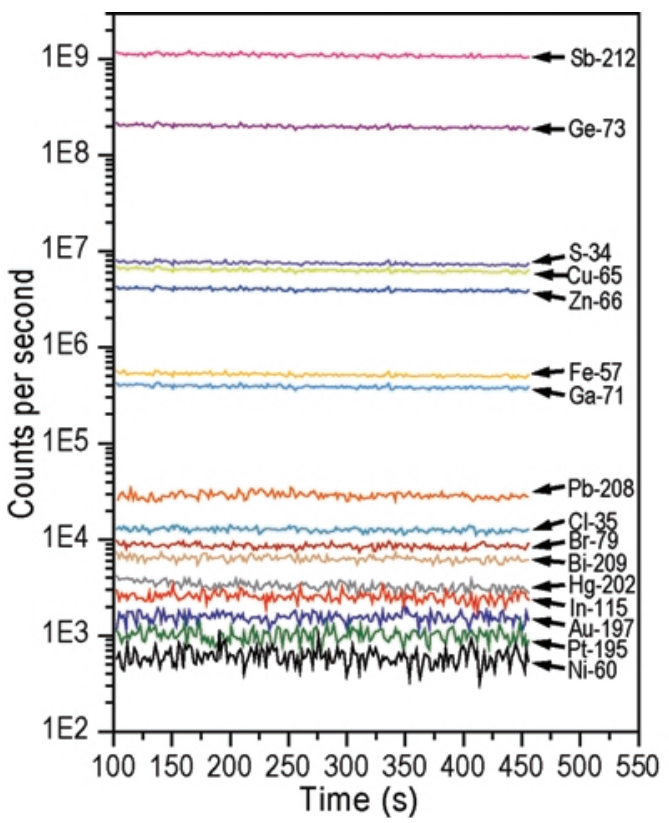

FIG. 6. Time resolved spectra for representative elements from a LA-ICP-MS line scan across a distance of $\sim 3000 \mu \mathrm{m}$ using a spot size of $60 \mu \mathrm{m}$. Note the excellent homogeneity of the major elements $(\mathrm{S}, \mathrm{Ge}, \mathrm{Sb})$ and reasonable homogeneity of the trace elements. pyrite specimens from Sunrise Dam, Western Australia, determined using IMER-1 as the calibration standard (from this study) and using STDGL2b-2 as the calibration standard (from the Sung et al., 2009, study) is shown in Table 3. The concentrations from the two analyses are comparable but this comparison can only act as a reference guide rather than a secondary calibration because the elements are somewhat heterogeneously distributed in the specimens (Sung et al., 2009). For example, the concentrations of As in specimen SU15 are $1282 \mathrm{ppm}$ and $1219 \mathrm{ppm}$, respectively, from the two analyses; in specimens SU311 and SU2, the values are also very close to each other. The concentrations of $\mathrm{Ni}$ in specimens SU311 and SU2 are within the same order of magnitude, but in SU15, the concentration determined by the current analysis is two orders of magnitude lower than that determined by Sung (2009). This comparison demonstrates that IMER-1 is a valid calibration standard for LAICP-MS determinations of trace elements in sulphide samples.

\section{Conclusions}

For LA-ICP-MS, a sulphide calibration standard, IMER-1, has been synthesized, in which four minor and 33 trace elements were incorporated into a chalcogenide glass matrix $\mathrm{Ge}_{28} \mathrm{Sb}_{12} \mathrm{~S}_{60}$. Preliminary chemical analyses of major and some 
TABLE 3. A comparison of the concentrations (part per million) of trace elements in natural pyrite specimens determined using LA-ICP-MS by this study using IMER-1 as the calibration standard and by Sung et al. (2009) using STDGL2b-2 as the calibration standard. The ablation spots for the current analyses were positioned adjacent to the spots selected by Sung et al. (2009).

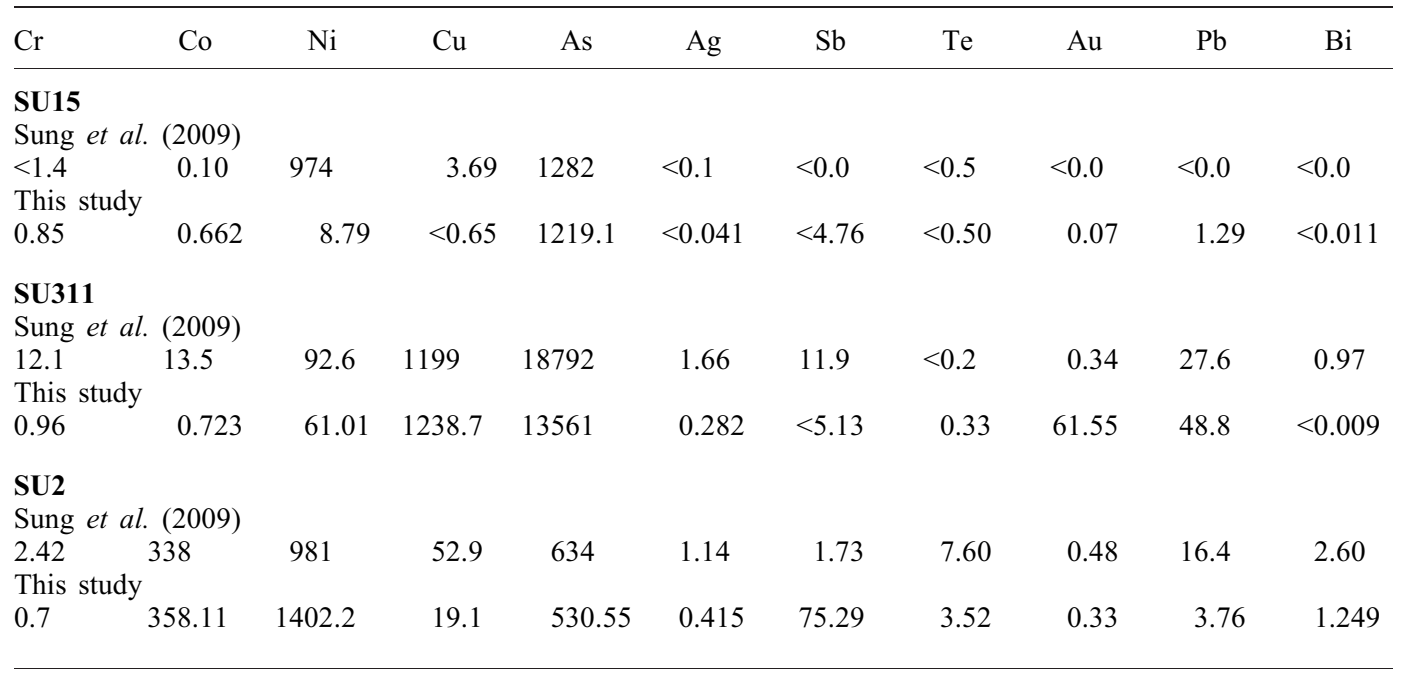

trace elements by EPMA, LA-ICP-MS, solution ICP-MS and ICP-OES confirmed acceptable homogeneity. The remeasurements of the trace element concentrations in three geological pyrite specimens previously measured by Sung (2009) demonstrated that IMER-1 may be an appropriate calibration standard for LA-ICP-MS determination of trace-element concentrations in sulphide specimens. The concentrations of some trace elements are $<1 \mathrm{ppm}$ due to the inefficient doping in the wet-chemical synthesis step and therefore a large beam size (e.g. $>60 \mu \mathrm{m})$ is recommended when using this standard, to reduce counting-statistics errors.

Compared to other methods, the present method has the following advantages: (1) the matrix-match problem can be overcome easily by using a sulphur-based glass matrix because the sulphur concentration can be adjusted within a fairly large glass-forming composition field $(50-75$ at.\%) to match the sulphur concentration of natural sulphides; (2) the loss of volatile species is avoided as chalcogenide glass is synthesized in sealed silica glass tubes; (3) the glass-forming element, $\mathrm{S}$, can be used as an internal standard during LA-ICP-MS analysis of sulphides because of the extreme homogeneity of $\mathrm{S}$ in the standard; (4) the preparation method offers the flexibility to produce standards for specific cases. This standard is complementary to the other available standards, because it contains a wider range of elements, has homogeneous distribution of $\mathrm{Au}$, and is suitable for determining very low concentrations (sub ppm levels) of elements in sulphides. Further development of a series of standards of this type with different doping elements and concentration levels $(10 \mathrm{~s}-1000 \mathrm{~s} \mathrm{ppm})$ is currently underway. Samples of the IMER-1 glass for use as a sulphide LA-ICP-MS standard are available from the author, A. Pring, for a nominal fee.

\section{Acknowledgements}

This work was supported financially by the Institute for Mineral and Energy Resources (IMER, The University of Adelaide), AngloGold (through an ARC linkage grant LP0454976), and the National Science Foundation of China (NSFC20906021). The authors thank Dr Yinsheng $\mathrm{Xu}$ (Ningbo University) for a preliminary EDS assessment of the sulphide mixture and Dr Benjamin Wade and Mr Angus Netting (Adelaide Microscopy) for technical assistance with EPMA and ICP-MS and also a critical reading of the manuscript. This is TRaX paper 
151 of the School of Earth and Environmental Sciences at the University of Adelaide.

\section{References}

Ballhaus, C. and Sylvester, P. (2000) Noble metal enrichment processes in the Merensky Reef, Bushveld Complex. Journal of Petrology, 41, 545-561.

Cabri, L.J., Sylvester, P.J., Tubrett, M.N., Peregoedova, A. and Laflamme, J.H.G. (2003) Comparison of LAM-ICP-MS and micro-pixe results for palladium and rhodium in selected samples of Noril'sk and talnakh sulfides. The Canadian Mineralogist, 41, 321-329.

Ciobanu, C.L., Cook, N.J., Pring, A., Brugger, J., Danyushevsky, L.V. and Shimizu, M. (2009) 'Invisible gold' in bismuth chalcogenides. Geochimica et Cosmochimica Acta, 73, 1970-1999.

Cook, N.J., Ciobanu, C.L., Pring, A., Skinner, W., Shimizu, M., Danyushevsky, L., Saini-Eidukat, B. and Melcher, F. (2009) Trace and minor elements in sphalerite: A LA-ICPMS study. Geochimica et Cosmochimica Acta, 73, 4761-4791.

Danyushevsky, L., Robinson, P., McGoldrick, P., Large, R. and Gilbert, S. (2003) LA-ICPMS of sulphides: Evaluation of an XRF glass disc standard for analysis of different sulphide matrixes. Geochimica et Cosmochimica Acta, 67, A73.

Dewaele, S., Muchez, P. and Hertogen, J. (2007) Production of a matrix-matched standard for quantitative analysis of iron sulphides by laser ablation inductively coupled plasma-mass spectrometry by welding: A pilot study. Geologica Belgica, 10, 109-119.

Norman, M.D., Pearson, N.J., Sharma, A. and Griffin, W.L. (1996) Quantitative analysis of trace elements in geological materials by laser ablation ICPMS: Instrumental operating conditions and calibration values of NIST glasses. Geostandards Newsletter the Journal of Geostandards and Geoanalysis, 20, 247-261.

Norman, M., Robinson, P. and Clark, D. (2003) Majorand trace-element analysis of sulfide ores by laserablation ICP-MS, solution ICP-MS, and XRF: New data on international reference materials. The
Canadian Mineralogist, 41, 293-305.

Reed, S.J.B. (2005) Electron Microprobe Analysis and Scanning Electron Microscopy in Geology. Cambridge University Press, Cambridge, UK, $192 \mathrm{pp}$.

Ridley, W.I. and Lichte, F.E. (1998) Major, trace and ultratrace element analysis by Laser Ablation ICPMS. Pp. 199-215 in: Application of Mineralogical Techniques in Understanding Mineralizing Processes (M.A. McKibben, W.C. Shanks III, and W.I. Ridley, editors). Reviews in Economic Geology, Special Publication 7.

Sung, Y.H., Brugger, J., Ciobanu, C., Pring, A., Skinner, W. and Nugus, M. (2009) Invisible gold in arsenian pyrite and arsenopyrite from a multistage Archaean gold deposit: Sunrise Dam, Eastern Goldfields Province, Western Australia. Mineralium Deposita, 44, 765-791.

Wilson, S.A., Ridley, W.I. and Koenig, A.E. (2002) Development of sulfide calibration standards for the laser ablation inductively-coupled plasma mass spectrometry technique. Journal of Analytical Atomic Spectrometry, 17, 406-409.

Wohlgemuth-Ueberwasser, C.C., Ballhaus, C., Berndt, J., Stotter née Paliulionyte, V. and Meisel, T. (2007) Synthesis of PGE sulfide standards for laser ablation inductively coupled plasma mass spectrometry (LAICP-MS). Contributions to Mineralogy and Petrology, 154, 607-17.

Xia, F., Zhang, X.H., Ren, J., Chen, G.R., Ma, H.L. and Adam, J.L. (2006) Glass formation and crystallization behavior of a novel $\mathrm{GeS}_{2}-\mathrm{Sb}_{2} \mathrm{~S}_{3}-\mathrm{PbS}$ chalcogenide glass system. Journal of the American Ceramic Society, 89, 2154-2157.

Xia, F., Baccaro, S., Wang, W., Pilloni, L., Zhang, X.H., Zeng, H.D. and Chen, G.R. (2008) Nanophase separation and effects on properties of Ge-As-Se chalcogenide glasses. Journal of Non-Crystalline Solids, 354, 1137-1141.

Zhao, D.H., Xia, F., Chen, G.R., Zhang, X.H., Ma, H.L. and Adam, J.L. (2005) Formation and properties of chalcogenide glasses in the $\mathrm{GeSe}_{2}-\mathrm{As}_{2} \mathrm{Se}_{3}-\mathrm{CdSe}$ system. Journal of the American Ceramic Society, 88, 3143-3146.

Zou, H. (2007) Quantitative Geochemistry. Imperial College Press, London, 304 pp. 